\title{
Effect of Lavender Oil on Relieving Post Cesarean Incisional Pain
}

\author{
Sally Ebrahim, Ragaa Ali, Mohamed Abd El-Hamed, Hadayat Abd EL-Raof, \\ head nurse in governmental hospital in manzala, Professor of Maternal \& Newborn \\ Health Nursing, in Faculty of Nursing, at Cairo University, Professor of Obstetrics \\ and Gynecology, in Faculty of Medicine, at Port-Said University,Assistant Professor \\ of Maternity, Gynecological and Obstetrical Nursing, in Faculty of Nursing, at Port- \\ Said University.
}

\begin{abstract}
This study aimed to evaluate the effect of lavender oil on relieving post cesarean incisional pain.A Quasi-experimental design was adopted in the current study. Setting: The study was conducted at the postpartum unit in Sueze-Canal University Hospital during the period from October 2013 to January 2014. A sample of convenience including 100 mothers was divided into two groups (study and control). Three tools were used for data collection, general charecteristic questionnaire, Visual Analogue Scale (VAS) and Modified Johansson Pain-O-Meter (MJPOM). The study group inhaled lavender oil and the control group received placebo. Results of the study showed highly statistically significant differences in pain intensity between the groups understudy $(\mathrm{p}<0.001)$, lavender oil was more effective with educated mothers and multiparous mothers. Conclusion; Lavender oil is a successful and safe complementary therapy in reducing pain after cesarean section. Results of the current study recommended that dissemination of lavender oil to all maternity hospital all over Egypt and added inhaled lavender oil into nursing curriculum in Port-Said.
\end{abstract}

Key Words: Aromatherapy, Cesarean section, .Lavender oil, Post cesarean pain. 


\section{Introduction}

Cesarean section (CS) is the almost common operation all over the world, the rate of this operation reaches near $50 \%$ of all types of deliveries (Ganji, Yusefi, \& Baradaran, 2006). Pain is a major problem in surgery, including caesarean section; post cesarean section pain is a common cause of pain in obstetrics, although pain relief and patient satisfaction are still inadequate in many cases (Centers for Disease Control and Prevention (CDC), 2005).

The pain presented after a cesarean section makes the recovery difficult and delays mothers to get in touch with the newborns, besides being an obstacle to a good breastfeeding position, self-care, newborn care, and to do daily activities, such as sitting down and standing up, walking and performing personal hygiene activities (Granot, Lowenstein, Yarnitsky, Tamir, \& Zimmer, 2004).

Lavender is one of the essential oils that are an adaptogen, meaning its properties adapt to your needs (Skidmore-Roth, 2010). Lavender essence is an aromatic herbal material with anti-pain properties. Lavender oil used to alleviate pain in different conditions such as changing dressings, palliative care, to control labor pain as well as chronic pain (Kim, Wajda, Cuff, Serota, \& Schlame, 2006).

\section{Significance of the study:}

Safe options of pain relief are women's dream of a perfect birth. Intervention for relieving post cesarean pain is a major part of modern obstetric care. Many women prefer to avoid pharmacological or invasive methods of pain management and this contributes to the popularity of complementary methods of pain management. Non pharmacological measures are safer and less side effects than pharmacological measures (Henry \& Nand, 2004). No previous study was conducted at Obstetric \& Gynecologic nursing department in Port-Said so this study was designed aimed to evaluate the effect of lavender oil on relieving post cesarean incisional pain.

Aim of the Study: The aim of this study is to evaluate the effect of lavender oil on relieving post cesarean incisional pain.

Hyposthesis: lavender oil highly significantly relieve post cesarean section incisional pain among mothers than among control group.

Subjects and methods: Setting: this study conducted at Postpartum Unit affiliated to Suez-Canal University Hospital Research Design: A quasi-experimental design was used in this study. Sample: A convenience sample of 100 postpartum with CS, they 
were assigned into two groups as their selection: group I was the study group consisted of 50 women \& group II was the control group consisted of 50 women.

\section{Tools of Data Collection}

Three tools were used to collect the necessary data for the study: Interview questionnaire sheet, Visual Analogue Scale (VAS), Modified Version of Johansson Pain-O-Meter (MJPOM).

\section{Tool (1): Interview questionnaire sheet:}

It was developed by the researcher to collect socio-demographic data, obstetrical history and factors affecting pain intensity.

\section{Tool (2): Visual Analogue Scale:}

It was developed by Melzack and Katz (1994) to assess the degree of pain.

\section{Tool III: Modified Version of Johansson Pain-O-Meter (MJPOM).}

It was developed by Johansson, 1973. It was used to measure the intensity of sensory and affective components of pain.

Operational Design: The Operational design includes preparatory phase and a pilot study

\section{Preparatory Phase:}

It was included revision of related literature, and theoretical knowledge of various aspects of the study using books, articles, internet periodicals and magazines to develop the tools for data collection. The tool was tested for content validity by 5 expert nurse educators from the Faculty of Nursing in Port-Said University, a second phase, to check for clarity.

\section{Pilot study:}

A pilot study was conducted on $10 \%$ of the total sample to test the feasibility of the study and applicability of the tool and to find out the possible obstacles and problems that might face the researcher and interfere with data collection and to detect any problems peculiar to the statements as sequence of questions and clarity. It also helped to estimate the time needed for data collection. After conducting the pilot study, it was found that the sentences of the tools were clear and relevant, but few words have been modified according to pilot study results. The samples of the women included in the pilot study were excluded from the main study sample. 


\section{Procedure of the study:}

The study proceeded as follows:

- Participants were assigned to two groups as their selection.

- Group I (study group). Fifty women who met the inclusion criteria of the study within 48 hours after cesarean section were take the routine treatment of the hospital as post cesarean pain relief measure, and after six hours, one cc of lavender oil was applied with a cotton swab to the inside of an oxygen face mask and used for three minutes, then the pain level was assessed after half an hour using the appendices II, III.

- Group II (control group). Fifty women who met the inclusion criteria of the study within 48 hours after cesarean section were takes the routine treatment of the hospital for pain relief measure, and after six hours, oxygen through a face mask with the placebo was used for three minutes, then the pain level was assessed using appendices II, III.

\section{Ethical Consideration:}

The purpose of the study was explained to each woman and a written consent was obtained from each of those who agreed to participate. They were assured about confidentiality and privacy and that this information will be used only for research purposes only.

\section{Statistical analysis of data}

After completion of data collection, data were organized and tabulated, and statistically analyzed. Data entry was done using Epi-Info 6.04 computer software package, while statistical analysis was done using the statistical package for social sciences (SPSS) version 15.0. Data were presented using descriptive statistics in the form of frequencies and percentages for qualitative variables, means and standard deviations for quantitative variables. 


\section{Results}

\section{The main findings of the present study were}

Table (1): shows that there was no statistically significant difference between both groups regarding their socio demographic data $(\mathrm{p}>0.05)$. It reveals that the age groups are between 21- 26 years, regarding level of education; the same table reveals that two thirds of the sample was educated. Considering occupation, table (1) indicates that the entire study group $100.0 \%$ was housewife compared to $96.0 \%$ of the control group.

Table (2): There was a highly statistically significant difference was found between both groups $(\mathrm{p}<0.001)$ according to $(\mathrm{VAS})$. The study group had experienced less pain intensity than the control group.

Table (3): shows that there was a statistically significant relation between the effect of lavender oil and educational level $(\mathrm{p}<0.05)$. Lavender oil was more effective between educated mothers rather than non-educated ones.

Table (4): shows that there was a highly statistically significant difference was found between the effect of lavender oil and parity $(\mathrm{p}<0.001)$. Lavender oil was more effective with multiparous than primiparous. 
Table (1): frequency distribution of both study and control group regarding their general characteristics $(N=100)$.

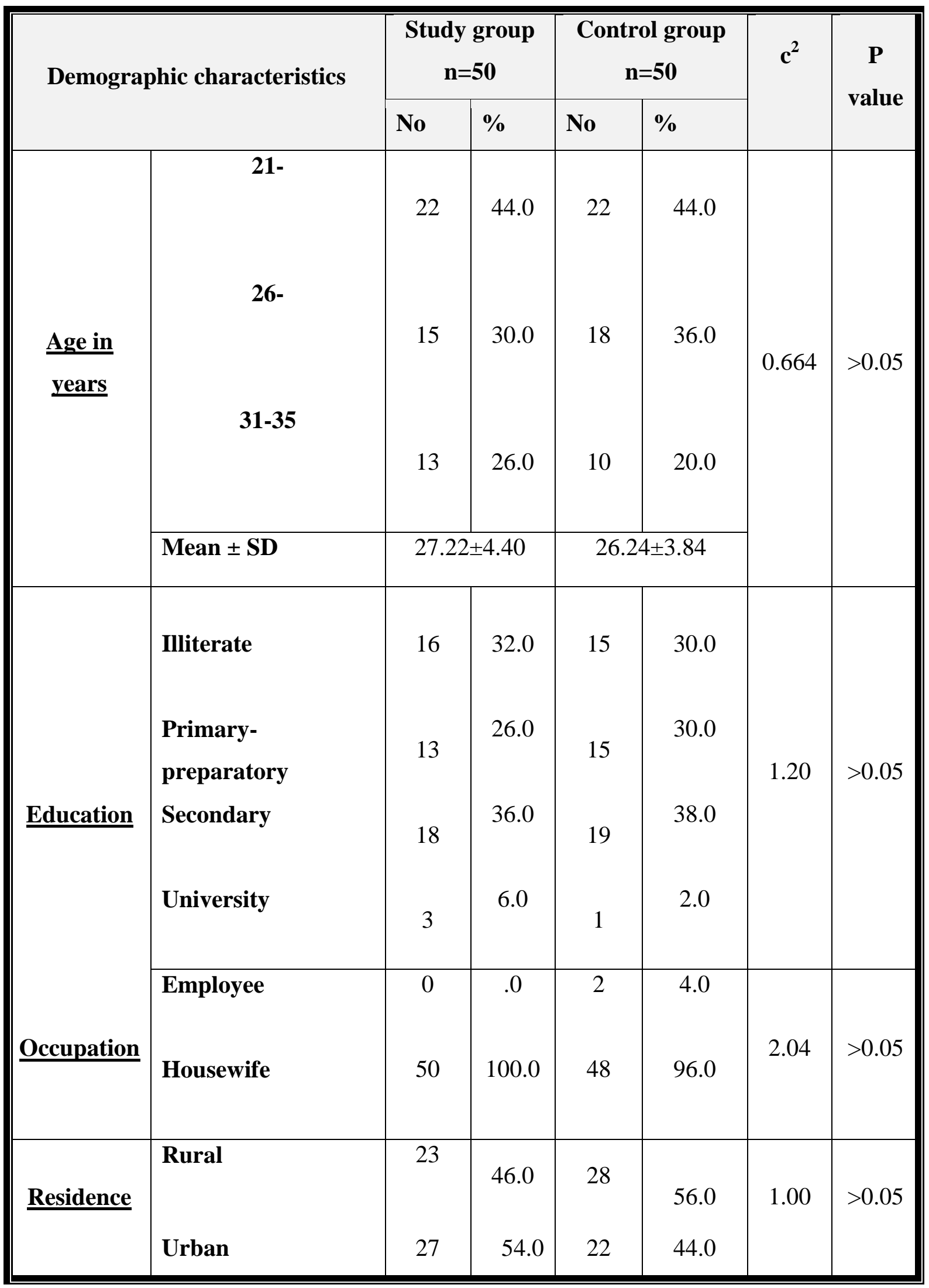


Table (2): frequency distribution of both study and control group regarding their pain score recorded by the visual analogue scale (VAS) $(\mathrm{N}=100)$.

\begin{tabular}{|c|c|c|c|c|c|c|}
\hline \multirow[t]{2}{*}{ Pain Score } & \multicolumn{2}{|c|}{$\begin{array}{l}\text { Study } \\
\text { Group } \\
(n=50)\end{array}$} & \multicolumn{2}{|c|}{$\begin{array}{l}\text { Control } \\
\text { Group } \\
(\mathbf{n}=\mathbf{5 0})\end{array}$} & \multirow[t]{2}{*}{$c^{2}$} & \multirow[t]{2}{*}{$\begin{array}{c}\mathbf{P} \\
\text { value }\end{array}$} \\
\hline & No & $\%$ & No & $\%$ & & \\
\hline Mild & 8 & 16.0 & 0 & 0.0 & \multirow{5}{*}{52.10} & \multirow{5}{*}{$<0.001 * *$} \\
\hline Moderate & 35 & 70.0 & 9 & 18.0 & & \\
\hline Severe & 6 & 12.0 & 11 & 22.0 & & \\
\hline Very severe & 0 & 0.0 & 16 & 32.0 & & \\
\hline Worst & 1 & 2.0 & 14 & 28.0 & & \\
\hline
\end{tabular}


Table (3): Relation between pain intensity according to the visual analogue scale and educational level to study group $(\mathrm{N}=50)$.

\begin{tabular}{|c|c|c|c|c|c|c|}
\hline \multirow{2}{*}{ Pain level / VAS } & \multicolumn{2}{|c|}{ Non-educated } & \multicolumn{2}{|c|}{ Educated } & \multirow{2}{*}{$\mathbf{c}^{2}$} & \multirow{2}{*}{$\begin{array}{c}\mathbf{P} \\
\text { value }\end{array}$} \\
\hline & No & $\%$ & No & $\%$ & & \\
\hline Mild & 0 & 0.0 & 7 & 14.0 & \multirow{4}{*}{16.29} & \multirow{4}{*}{$<0.05^{*}$} \\
\hline Moderate & 13 & 26.0 & 24 & 48.0 & & \\
\hline Severe & 3 & 6.0 & 3 & 6.0 & & \\
\hline Very severe & 0 & 0.0 & 1 & 2.0 & & \\
\hline
\end{tabular}


Table (4): Relation between pain intensity according to the visual analogue scale and parity for the study group $(\mathrm{N}=50)$.

\begin{tabular}{|c|c|c|c|c|c|c|c|c|}
\hline \multirow{3}{*}{ Pain scorel VAS } & \multicolumn{6}{|c|}{ Parity } & \multirow{3}{*}{$c^{2}$} & \multirow{3}{*}{ p-value } \\
\hline & \multicolumn{2}{|c|}{1} & \multicolumn{2}{|c|}{2} & \multicolumn{2}{|c|}{3} & & \\
\hline & No & $\%$ & No & $\%$ & No & $\%$ & & \\
\hline Mild & 0 & 0.0 & 0 & 0.0 & 6 & 12.0 & & \\
\hline Moderate & 1 & 2.0 & 11 & 22.0 & 25 & 50.0 & & \\
\hline Severe & 5 & 10.0 & 1 & 2.0 & 0 & 0.0 & & \\
\hline Very severe & 1 & 2.0 & 0 & 0.0 & 0 & 0.0 & & \\
\hline
\end{tabular}




\section{Discussion}

The aim of present study was to evaluate the effect of lavender oil on relieving post caesarean section incisional pain. This aim was highly significantly answered through the present study findings. According to the results yielded by the present study, lavender oil inhalation after caesarean section was useful in relieving post cesarean section pain; there was a statistically significant difference in pain intensity between the study and control groups $(\mathrm{p}<0.001)$. The current study showed that the lavender oil is more effective with multiparous and educated mothers $(p<0.05)$.

The main results of Hadi and Hanid (2011) study, showed significant reduction in pain level at half an hour after lavender oil use post elective cesarean section. An important reduction was seen in pain at half, eight and 16 hours after intervention in the group using inhaled lavender. However, the current study assessed pain intensity after half hour only and pain reduction was seen after half an hour.

The current study result is in accordance with Sheikhan et al. (2012) study on episiotomy pain using lavender oil bath, who found that pain in the Lavender group at four hours and also five days after delivery was significantly reduced. In relation to parity, the current study involved primiparous and multiparous, but Sheikhan et al., (2012) conducted their study only on primiparous women.

In addition, Olapour et al. (2013) mentioned that mothers in the lavender group had less post cesarean section pain after four hours $(\mathrm{p}=0.008)$, eight hours $(\mathrm{p}=0.024)$, and twelve hours $(\mathrm{p}=0.011)$ after first medication than the placebo group. However, the current study result revealed reduction on pain level after six hours only after medication.

In disagreement with Vakilian et al, (2010), found that there was no significant difference between the two groups in pain scores on episiotomy. While the current study was showed a statistically significant difference between the two groups in pain score $(\mathrm{p}<0.001)$. Vakilian et al, (2010) conducted their study on primiparous women only, while the current study showed that lavender oil was more effective with multiparous women. 
Moreover, in a study conducted by Smith et al. (2010), there was no difference between the women receiving aromatherapy and women who did not during normal labour. As well, in a study by Jones et al. (2012) who noticed that there was no evidence of a significant difference between groups in pain intensity comparing aromatherapy with standard care for assisted vaginal birth or caesarean section.

However, the current study was in accordance with a very recent study of Soltani et al. (2013) who noticed that aromatherapy with lavender essential oil had analgesic effect and decreased the number of required analgesics following tonsillectomy in pediatric patients. The current study was not determining the number of required analgesics.

The present study findings go in line with Vakilian et al. (2012) concluded that aromatherapy with lavender essence inhalation were a suitable alternative complementary medicine for labor pain, and also Nesami et al. (2014) found that lavender aromatherapy may be an effective technique to reduce pain following needle insertion into a fistula in hemodialysis patients.

\section{Conclusion}

In the light of the findings of the current study, it can be concluded that lavender oil inhalation can be used as an effective nursing initiative in post cesarean section pain control. Lavender oil was observed to be an effective method in postoperative pain control with a higher rate of success in reducing pain intensity with comparison to placebo treatment.

\section{Recommendation}

Based on the findings of the present study, the following recommendations were suggested:

- Lavender oil inhalation could be recommended to be included in maternal hospital protocol for management of post cesarean pain.

- Lavender oil inhalation for relieving post cesarean pain may be added in maternal nursing curricula of nursing schools in Port-Said. 
- Health education to women about the effect of lavender oil on relieving post cesarean pain so that they will be knowledgeable about its benefits.

- Maternity nursing staff knowledge should be regularly updated their knowledge about non pharmacological pain relievers.

- It is recommended that pregnant women receive information by health care team during ante natal care and at the time of admission for operating room about the benefits of lavender oil inhalation use after cesarean section.

\section{References}

Centers for Disease Control and Prevention (CDC). (2005).

Ganji, F., Yusefi, H., \& Baradaran, A. (2006). Effect of a participatory intervention to reduce the number of unnecessary cesarean sections performed in shahrekord of Iran J. Medical Sci; 6, 690-692.

Granot, M., Lowenstein, L., Yarnitsky, D., Tamir, A., \& Zimmer, E.Z. (2004). Post cesarean section pain prediction by preoperative experimental pain assessment. Anesthesiol; 98(6), 1422-6.

Hadi, N., \& Hanid, A.A. (2011), Lavender essence for post cesarean pain. Pakistan Journal of Biological Sciences; 14(11), 664.667.

Jones, L., Othman, M., Dowswell, T., Alfirevic, Z., Gates, S., Newburn, M., Jordan, S., Lavender, T., \& Neilson, J.P. (2012). Pain management for women in labour: an overview of systematic reviews (Review). The Cochrane Library, Issue 3.

Kim, J.T., Wajda, M., Cuff, G., Serota, D., Schlame, M., Axelrod, D.M., Guth, A.A., \& Bekker, A.Y. (2006). Evaluation of aromatherapy in treating postoperative pain: Pilot study. World Institute of Pain Practice; 6(4), 273-277.

Nesami, M.B., Espahbodi, F., Nikkhah, A., Shorofi, S.A., \& Charati, J.Y. (2014). The effects of lavender aromatherapy on pain following needle insertion into a fistula in hemodialysis patients. Elsevier J; 20, 1-4.

Olapour, A., Behaeen, K., Akhondzadeh, R., Soltani, F., Razavi, S.F., \& Bekhradi, R. (2013). The Effect of Inhalation of Aromatherapy Blend containing Lavender Essential Oil on Cesarean Postoperative Pain. Anesthesiol Pain Med; 3(1), 203-7.

Sheikhan, F., Jahdi, F., Khoei, E.M., Shamsalizadeh, N., Sheikhan, M., \& Haghani, H. (2012). Episiotomy pain relief: Use of Lavender oil essence in primiparous Iranian women. Elsevier J; 18, 66-70. 
Skidmore-Roth, L. (2010). "Lavender". Mosby's Handbook of Herbs \& Natural Supplements. 4th edition. Elsevier Health Sciences.

Smith, C.A., Collins, C.T., Cyna, A.M., \& Crowther, C.A. (2010). Complementary and alternative therapies for pain management in labour (Review). The Cochrane Library, Issue 9.

Soltani, R., Soheilipour, S., Hajhashemi, V., Asghari, G., Bagheri, M., \& Molavi, M. (2013). Evaluation of the effect of aromatherapy with lavender essential oil on posttonsillectomy pain in pediatric patients: A randomized controlled trial; 9(77), 15791581.

Vakilian, K., Atarha, M., Bekhradi, R., \& Chaman, R. (2010). Healing advantages of lavender essential oil during episiotomy recovery: a clinical trial. Complement Ther Clin Pract; 17(1), 34-40.

Vakilian, K., Karamat, A., Mousavi, A., Shariati, M., Ajami, E., \& Atarha, M. (2012). The effect of lavender essence via inhalation method on labor pain. shahrekord univ med sci j; 14(1), 34-40. 


\section{دراسة الفعالية لزيت اللافندر على تخفيف آلام ما بعد الولادة القيصرية فى مستشفى جامعة قناة|لسويس}

\section{الملخص العربى}

التحكم الآمن فى حدة الألم بعد الو لادة القيصرية يمثل تحدى كبير بالنسبة للفريق الطبى وذلك

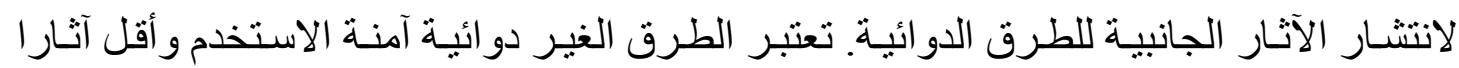

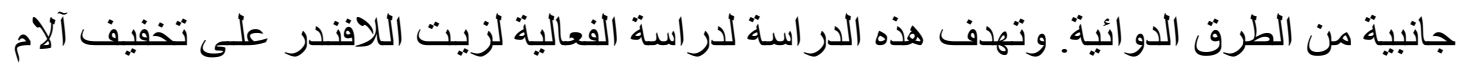

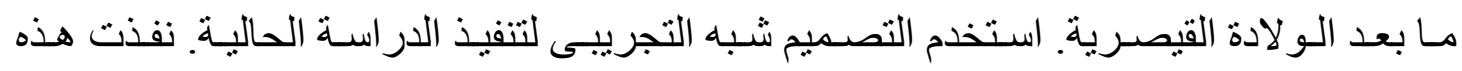

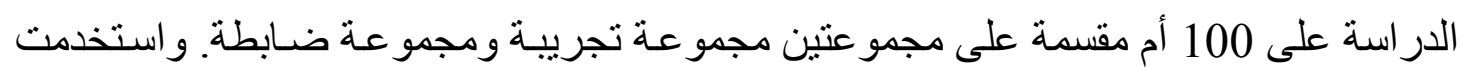

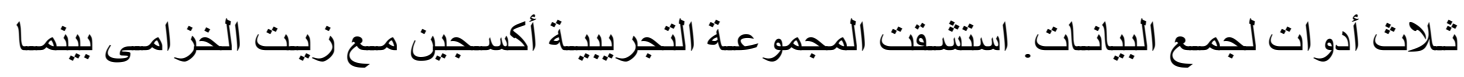
المجمو عة الضابطة استتشقت الأكسجين بدون زيت الخزامى. وقد أسفرت النتائج على وجود

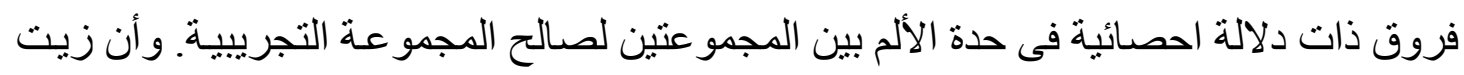

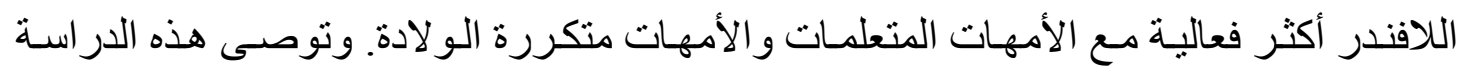
باستخدام زيت الخز امى على عينة كبيرة ومجمو عات سكانية مختلفة. 